in the urine, but extent of activation was not highly correlated with any single urinary $\mathrm{PAH}-\mathrm{OH}$ marker.

Conclusion Among firefighters, urinary $\mathrm{PAH}-\mathrm{OH}$ concentrations increase in both entry teams and engineers. The route and extent of dermal and inhalation exposure vary with the specific job task at the fireground. AhR and p53 in vitro bioassays demonstrate activation of cancer pathways following occupational exposure in firefighters.

\section{HUMAN BIO-MONITORING OF EPOXY RESINS AND HARDENERS IN THE PRODUCTION OF ROTOR: BLADES}

${ }^{1} \mathrm{~T}$ Schettgen, ${ }^{1} \mathrm{M}$ Krichels, ${ }^{2} \mathrm{~B}$ Rossbach, ${ }^{1} \mathrm{~T}$ Kraus. IInstitute of Occupational and Social Medicine, RWTH Aachen University; ${ }^{2}$ Institute of Occupational, Social and Environmental Medicine, University Medical Centre of the Johannes Gutenberg-University, Mainz

\subsection{6/oemed-2018-ICOHabstracts.1179}

Introduction In a small company producing rotor blades for aviation from carbon composites, epoxy resins based on Novolac and isophorone diamine as hardener are used. Both compounds can be absorbed via skin contact and were shown to be strong skin sensitizers. As a part of risk assessment, the industrial physician prompted a biological monitoring to determine the internal exposure of the workers.

Methods 6 workers were identified with potential contact to the hardener and resin. We have collected pre- and post-shift urine samples at the beginning and mid of the work week and analysed them for the concentration of isophoronediamine and bisphenol-f-diglycidylethermetabolites as biomarker for the hardener and Novolac via specific mass spectrometric methods.

Results We detected isophoronediamine in almost all urine samples with post-shift-values significantly higher than preshift. Median urinary excretion of isophoronediamine over the workweek was $195 \mu \mathrm{g} / \mathrm{g}$ crea. (Monday pre-shift), $709 \mu \mathrm{g} / \mathrm{g}$ crea. (Monday post-shift), $573 \mu \mathrm{g} / \mathrm{g}$ crea. (Wednesday pre-shift) and $1319 \mu \mathrm{g} / \mathrm{g}$ crea. (Wednesday post-shift). Results for urinary bisphenol-f-diglycidylether-metabolites were several orders of magnitude lower and near the limit of detection $(0.5 \mu \mathrm{g} / \mathrm{L})$.

Conclusion We found considerable internal exposures to isophoronediamine in workers producing carbon composite rotor blades. Our results indicate a cumulating internal exposure over the work-week. One of the workers showed clinical symptoms of allergic contact dermatitis in the skin examination. Use of inappropriate gloves was determined to be the cause for these high exposures. Biological monitoring should be part of risk assessment of workers handling epoxy resins.

\section{EXPOSURE FROM GUN SMOKE ACTIVATES SEVERAL SYSTEMIC INFLAMMATORY PATHWAYS}

\footnotetext{
${ }^{1,2} \mathrm{~J}$ Kongerud, ${ }^{3,4} \mathrm{AK}$ Borander, ${ }^{5} \varnothing$ Voie, ${ }^{6} \mathrm{R}$ Øvstebø, ${ }^{5} \mathrm{~K}$ Longva, ${ }^{7} \mathrm{NE}$ Alexis, ${ }^{1,8} \mathrm{~T}$ Ueland, 1,2LIB Sikkeland. 'Institute of Clinical Medicine, Faculty of Medicine, University of Oslo, Olso, Norway; ${ }^{2}$ Department of Respiratory Medicine, Oslo University Hospital Rikshospitalet, Oslo, Norway; ${ }^{3}$ Department of Environmental and Occupational Medicine, Oslo University Hospital, Oslo, Norway; ${ }^{4}$ The Occupational Health Service in the Norwegian Armed Forces, Sessvollmoen, Norway; ${ }^{5}$ Norwegian Defence Research Establishment, Division Protection, Kjeller, Norway; ${ }^{6}$ The Blood Cell Research Group, Dept. of Med. Biochemistry, Oslo Univ. Hosp. Ullevål, Oslo, Norway; ${ }^{7}$ Center for Environmental Medicine, Asthma and Lung Biology, UNC Chapel Hill, North Carolina, USA; ${ }^{8}$ Research Institute of Internal Medicine, Oslo University Hospital. Rikshospitalet, Oslo, Norway
}

10.1136/oemed-2018-ICOHabstracts. 1180
Introduction Norwegian Armed Forces reported episodes of acute respiratory symptoms after exposure to fumes from firing small arms weapon HK416 (Heckler and Koch) using unleaded ammunition. These fumes contain a mixture of gases and solid particles, that may be capable of inducing inflammatory immune responses. The aim of the present study was to find out if exposure to fumes from small arms could induce systemic and airway inflammation, and whether there were any differences between the ammunition types (leaded, and two types of unleaded).

Methods Fifty-five healthy men (age 19-62) were recruited and randomised to three groups using HK416 and one of the three types of ammunition. Spirometry and collection of blood and sputum samples were performed 2-4 days before shooting, and 1.5 hour (spirometry), 24 hour (blood and spirometry) and 48 hour (sputum) after shooting under standardised conditions. Exposure was monitored.

Results All subjects had a significant increase in median sputum and blood neutrophils (sputum: $46 \%$ to $73 \%, \mathrm{p}<0.001$; blood: $2.9 \times 10^{6} / \mathrm{mL}$ to $\left.7.1 \times 10^{6} / \mathrm{mL}, \mathrm{p}<0.001\right)$. CRP was significantly elevated from $1.3 \mathrm{mg} / \mathrm{L}$ to $18.5 \mathrm{mg} / \mathrm{L}(\mathrm{p}<0.001)$ along with other markers of systemic inflammation (PTX3, YKL-40, SpD, CC16, CXCL16, vWF, MPO, CD25, CD14). CRP and number of neutrophils in blood had a larger increase with unleaded as compared to leaded ammunition. For the whole group, mean $\mathrm{FEV}_{1}$ and FVC decreased $290 \mathrm{~mL}$ $(\mathrm{p}<0.001)$ and $130 \mathrm{~mL}(\mathrm{p}<0.001)$, respectively.

Discussion All subjects displayed elevated airway and in particular systemic inflammation following the use of small arms. The changes in systemic markers were enhanced acute stress response (CRP, PTX3), immune cell upregulation (sCD25, sCD14) and increased vascular inflammation (MPO, vWF, CXL16, YKL40). Increased airway inflammation was present at 48 hour post exposure and was accompanied by reduced spirometry that appeared $<1.5$ hour and lasted $>24$ hour after exposure. These results suggest that soldiers may be at increased risk to inflammation-based disorders when repeatedly using small arms.

\section{COMBINATION OF CELLULAR ASSAYS WITH METABOLOMICS REVEALED MECHANISTIC INSIGHTS ON DOSE-RESPONSE RELATIONSHIP OF 3- NITROBENZANTHRONE IN HUMAN UROTHELIAL CANCER CELLS}

Simone Schmitz-Spanke*, Nisha Verma, Anna Zerries, and Mario Pink. Institute and Outpatient Clinic of Occupational, Social and Environmental Medicine, University of Erlangen-Nuremberg, Schillerstr, 25/29, 91054 Erlangen, Germany

\subsection{6/oemed-2018-ICOHabstracts.1181}

Introduction A product of incomplete combustion of diesel fuel, 3-nitrobenzanthrone (3-NBA), has been classified as a cancer-causing substance. It gained attention as a potential urinary bladder carcinogen due to the presence of its metabolite in urine and formation of DNA adducts.

The aim of this study was to characterise the dose-response relationship starting from environmentally relevant to high concentrations by utilising toxicological and metabolomic approaches to determine the toxic potential of 3-NBA in bladder cells.

Method Cells of RT4 cells were exposed against $0.3 \mathrm{nM}$ to $80 \mu \mathrm{M} 3-\mathrm{NBA}$ for 24 hour. Both activity of enzymes involved in the metabolism of $3-\mathrm{NBA}$ as well as cytotoxicity were 
determined using specific assays. Finally, the potential of 3NBA to alter the cellular metabolism was assessed by gas chromatography-mass spectrometry.

Result RT4 cells were capable of bioactivation of 3-NBA within $30 \mathrm{~min}$, whereas the main contributor for bioactivation of 3-NBA was $\mathrm{NAD}(\mathrm{P}) \mathrm{H}$ :quinone oxidoreductase (NQO1). Cytotoxicity assessment revealed an activation of adaptive mechanisms at low dosages, which diminished at higher doses.

The metabolomic analysis of the cells showed elevated levels of various antioxidants at low concentrations of 3-NBA. At higher exposure concentrations, it appeared that the cells reprogrammed their metabolism to maintain the pentose phosphate pathway (PPP) aiding in cell protection.

Discussion Starting from a relevant environmental dose of $0.0003 \mu \mathrm{M}$ up to $80 \mu \mathrm{M}$, we described the driving mechanism behind the different cellular states - in particular an activation of adaptive mechanisms at low dosages, which diminished at higher doses. The metabolomic data suggested that the PPP and the folate metabolism play a leading role in this transition. Moreover, there was evidence for an additional carbon flux into PPP via the gluconate metabolism to support the formation of NADPH, which in term is an important determinant of the defence system against oxidative stress.

\section{HEART RATE VARIABILITY IN SMELTER FURNACE WORKERS}

${ }^{1} \mathrm{MD}$ Bugge*, ${ }^{1} \mathrm{~B}$ Ulvestad*, ${ }^{1} \mathrm{~B}$ Berlinger*, ${ }^{1} \varnothing$ Skare*$^{*},{ }^{2} \mathrm{~K}$ Gjesdal*, ${ }^{1} \mathrm{DG}$ Ellingsen*. 'STAMI, National Institute of Occupational Health, Oslo, Norway; ${ }^{2}$ Oslo University Hospital, Oslo, Norway

\subsection{6/oemed-2018-ICOHabstracts.1182}

Introduction Exposure to fine particulate matter in urban air has been associated with increased risk of hospitalisation and death from cardiovascular diseases. One hypothesis suggests a direct influence of particles on the autonomic nervous system. Some studies have shown an association between particle exposure and reduced heart rate variability (HRV). Furnace workers in metal smelters are occupationally exposed to fine and ultrafine particles. The aim of this study was to examine the association between exposure to particulate matter in metal smelters and HRV.

Methods We examined 64 workers in three Norwegian metal smelters on a working day, and on a day off after at least two days since last exposure. On the working day, exposure to different particle size fractions was assessed by personal sampling, using respirable cyclones and five-stage Sioutas cascade impactors. The workers carried Holter monitors for 24 hours' heart rate registration during the working day and the day off. HRV indices were analysed by exposure for each hour of the day, using mixed model regression, adjusted for relevant covariates.

Results There were 58 male and 6 female workers. Their mean age was 34 years (range 19-64). The mean exposure to respirable particulate matter was $2.36 \mathrm{mg} / \mathrm{m}^{3}$, while $0.88 \mathrm{mg} /$ $\mathrm{m}^{3}$ was below $250 \mathrm{~nm}$. Standard deviation of normal-to-normal intervals (SDNN) was reduced during working hours on the working day relative to the day off, whereas in the afternoon and night hours there were no significant differences. Low frequency/high frequency $(\mathrm{LF} / \mathrm{HF})$ ratio was higher during working hours on the working day, but in the afternoon and evening hours the LF/HF ratio was significantly higher on the day off compared to the working day.
Conclusion HRV indices differ between working day and day off. Analyses are in progression, and further results on the effects of particle exposure will be presented.

\section{CONTRIBUTIONS OF DERMAL VS AIR EXPOSURE TO BIOMONITORING FOR SOLVENT EXPOSURE}

${ }^{1}$ Matteo Creta*, ${ }^{2}$ Horatiu Moldovan, ${ }^{3}$ Septimiu Voidazan, ${ }^{1,4}$ Lode Godderis, ${ }^{1}$ Radu Corneliu Duca, 'Jeroen Vanoirbeek. 'Environment and Health, University of Leuven (KU Leuven), Belgium; ${ }^{2}$ Occupational Medicine Department, University of Medicine and Pharmacy of Tirgu-Mures, Romania; ${ }^{3}$ Epidemiology Department, University of Medicine and Pharmacy of Tirgu-Mures, Romania; ${ }^{4} / d e w e$, External Service for Prevention and Protection at Work, Heverlee, Belgium

\subsection{6/oemed-2018-ICOHabstracts. 1183}

Introduction Dermal exposure assessment is becoming increasingly important in occupational settings, but its contribution to the overall body burden is not yet well-established. Therefore, we evaluated the contribution of dermal exposure to the total body burden as reflected by biomonitoring, by simultaneous quantitative assessment of dermal, and air exposure in combination with bio- monitoring, in workers exposed to solvent.

Methods Exposure to the volatile organic compounds, styrene, acetone and toluene on the skin was evaluated using activated charcoal cloth patches; inhalation exposure was measured using passive organic vapour monitors, and systemic exposure was assessed by quantification of mandelic acid, acetone and hyppuric acid in urine, as biomarkers for styrene, acetone and toluene, respectively. Exposure was measured in 40 workers performing different tasks: hydraulic press (HP) workers, sheet moulding composite (SMC) workers, mechanics and office workers in a thermoplastic panels factory.

Results For styrene, the dermal exposure levels found were higher for HP workers $\left(1532 \pm 450 \mu \mathrm{g} / \mathrm{cm}^{2}\right)$ than for the other workers (e.g. SMC 179 \pm 50 ). Inhalation exposure levels for $\mathrm{HP}$ and SMC workers were similar $\left(58 \pm 11 \mathrm{mg} / \mathrm{m}^{3}\right.$ and $60 \pm 8$ $\mathrm{mg} / \mathrm{m}^{3}$, about $70 \% \mathrm{TLV}$ ), but urinary concentrations of mandelic acid were higher for HP $(549 \pm 85 \mu \mathrm{g} / \mathrm{mL})$ then SMC $(331 \pm 21 \mu \mathrm{g} / \mathrm{mL})$ workers. In addition, a good correlation between dermal, air and urinary levels of acetone was found. Unlike for styrene and acetone, toluene levels in air were less than $1 \%$ TLV, regardless of the tasks performed by the workers. No relevant dermal or inhalation exposure was found for mechanics and office workers.

Discussion This study shows that for solvents, high dermal exposure substantially contributed to the increased concentrations of urinary metabolites. Therefore, the contribution of dermal exposure to the overall body burden is as important as the respiratory exposure, especially for less-volatile solvents, such as styrene.

\section{ORGANOPHOSPHATES IN THE WORKPLACE: A 20-YEAR PROSPECTIVE STUDY}

${ }^{1} \mathrm{~N}$ Loio-Marques, ${ }^{2} \mathrm{M}$ Felgueiras, ${ }^{3} \mathrm{~L}$ Guilhermino, ${ }^{4} \mathrm{C}$ Valls-Llobet. ${ }^{1}$ Occupational Medicine Resident, Centro Hospitalar Porto, Porto, Portugal; ${ }^{2}$ Clinical Pathology Resident, Centro Hospitalar Cova da Beira, Covilhã, Portugal; ${ }^{3}$ PhD Biology, Instituto Ciências Abel Salazar, Porto, Portugal; ${ }^{4}$ Endocrinologist, Centre d'Atenció i Programes Sanitaris, Barcelona, España

\subsection{6/oemed-2018-ICOHabstracts. 1184}

